\title{
Congratulatory note
}

\author{
M. Jarraud • Y. S. Chung
}

Received: 17 April 2008 /Revised: 18 April 2008 /Accepted: 18 April 2008 / Published online: 24 May 2008

(C) Springer Science + Business Media B.V. 2008

On the occasion of the launch of the International Journal Air Quality, Atmosphere \& Health, it is a pleasure for me to congratulate Springer and the Editors, Y.S. Chung and J.M. Samet, on behalf of the World Meteorological Organization (WMO), for this opportune contribution in bridging the growing gap between the highly specialized and the multidisciplinary scientific literature in this wide-ranging and crucial field.

In 2007, the Intergovernmental Panel on Climate Change (IPCC), co-sponsored since 1988 by WMO and the United Nations Environment Programme (UNEP), received the Nobel Peace Prize for its efforts "to build up and disseminate greater knowledge about man-made climate change, and to lay the foundation for the measures that are need to counteract such changes." The IPPC recently released its Fourth Assessment Report, unequivocally underscoring the vital relevance of critical contemporary issues such as global warming, climate change, and the protection of the environment.
At the level of the United Nations System, climate change has been recognized as a top-priority issue and is therefore considered on equal standing with other major crises that humanity is currently experiencing. The challenges involved will increasingly demand expanded multidisciplinary research, partnerships and scientific observations, which clearly highlight the very important contributions that the International Journal Air Quality, Atmosphere \& Health will be capable of providing at this vital juncture.

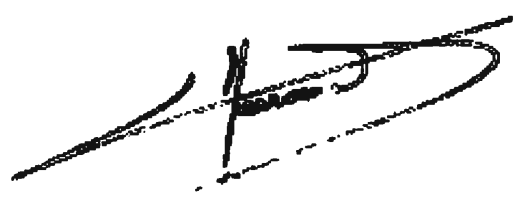

(M. Jarraud)

Secretary-General of the World Meteorological Organization

\footnotetext{
M. Jarraud

World Meteorological Organization,

Geneva, Switzerland

\section{Y. S. Chung $(\bowtie)$}

Korea Centre for Atmospheric Environment Research,

304 Koonghyon, Khangnae,

Cheongwon, Choongbook 363-891, South Korea

e-mail: kccar1@kornet.net
} 